\section{Genomic Medicine Takes the Stage, Again!}

Last month I made my annual pilgrimage to the ASCO Annual Meeting. As usual, I was dazzled (and sometimes frazzled) by the wealth of new information, breakthroughs in oncology care, and vibrancy of our oncology community. What a show!

I was glad to see the results of TAILORx at the Plenary Session. The diagnostic genomic test Oncotype DX from Genomic Health has been used routinely in the clinic for some time to predict the likelihood of recurrence in patients with breast cancer at low risk for recurrence. The TAILORx study was designed to validate the use of the test in patients with early-stage breast cancer at intermediate risk for recurrence. Based on its findings, 70\% of these patients can safely avoid adjuvant chemotherapy. This is a triumph for patients, for sure. Avoiding chemotherapy and the long-term consequences of treatment is a good thing. It's also a triumph for curbing the cost of care. Obviously, no treatment means no cost. We need a lot more of that!

It stands to reason that in the adjuvant setting, we could probably identify diagnostic tools to predict outcome, and thus need for adjuvant treatment, across all disease sites. Actually, folks are working on that with a fair bit of success. But adjuvant therapy is kind of black or white: you either do it or you don't. In cancer medicine, we have a lot of gray areas, and I sometimes struggle to understand how these will be sorted out.

To me, gray areas are mostly about intensity and duration of therapy. Is 3 or 4 months of adjuvant therapy as good as 6 ? Can you treat with tyrosine kinase inhibitors intermittently rather than every day? Is a chemotherapy regimen with lots of side effects just as effective if you give lower doses? Does a chemotherapy holiday put a patient at increased risk for progression? These are practical considerations that we face all the time.

For a lot of reasons, we don't seem to have the same appetite for answering these questions. For one thing, our usual structures for clinical trials involve a sponsor with a new product or our federally funded clinical trials network. You would think the latter would take these questions on, and sometimes it does. But not as often as I think it could.

Who are the stakeholders for these gray zones? Certainly the patients who want a good outcome along with an easier path to success are stakeholders, but it seems to me that our payers, including the Centers for Medicare \& Medicaid Services (CMS), ought to be pretty enthusiastic about approaches using fewer drugs or with fewer side effects that can also drive down the cost of care. So is it unreasonable to ask them to step forward and support clinical trials to help us answer these questions? Personally, I think it's time for this to happen, and I would hope we could look to CMS for some leadership.

I haven't done the math for any given scenario, but I think that surely certain investments here could reap big rewards. Do you agree? Then let me know!

What do you think? Please e-mail correspondence (include contact information) to JNCCN@nccn.org or log into www.editiorialmanager.com/JNCCN to submit a Letter to the Editor.

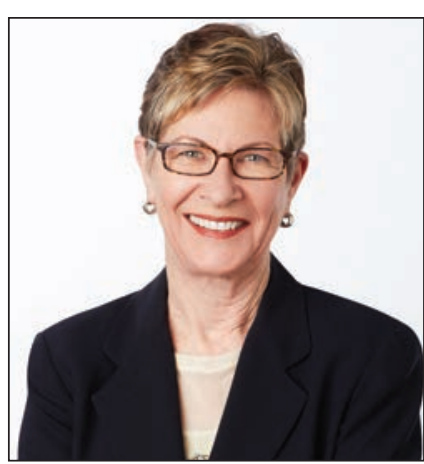

Margaret Tempero, MD

Margaret Tempero, MD, is a Professor of Medicine and Director of the UCSF Pancreas Center and editor-in-chief of JNCCN. Her research career has focused on pancreatic ductal adenocarcinoma, especially in the area of investigational therapeutics. Dr. Tempero has served on the ASCO Board of Directors and as ASCO President. She currently serves on the ASCO Conquer Cancer Foundation Board. She codirected the AACR/ASCO Methods in Clinical Cancer Research and taught this course and similar courses in Europe and Australia. She was founding Chair of the $\mathrm{NCl}$ Clinical Oncology Study Section and served as a member and Chair of the NCl Board of Scientific Counselors Subcommittee $A$. She is a member of the Scientific Steering Committee and Chair of the Clinical and Translational Study Section for the Cancer Prevention \& Research Institute of Texas. She is or has been on the Scientific Advisory Boards of the Lustgarten Foundation, the Pancreatic Cancer Action Network, the $V$ Foundation, The Alberta Canada Cancer Board, and the EORTC. She served as a member of the Oncology Drug Advisory Committee for the FDA. She has served as Deputy Director and Interim Director for the UNMC Eppley Cancer Center. She is Chief Emeritus of the Division of Medical Oncology at UCSF and served as the founding Deputy Director and Director of Research Programs at the UCSF Helen Diller Family Comprehensive Cancer Center.

doi: $10.6004 / j n c c n .2018 .0063$

The ideas and viewpoints expressed in this editorial are those of the author and do not necessarily represent any policy, position, or program of NCCN. 